\title{
Morbidity among employees engaged in the manufacture or formulation of chlorpyrifos
}

\author{
F E BRENNER, ' G G BOND, ${ }^{2}$ E A MCLAREN,' S GREENE, ' R R COOK ${ }^{2}$
}

From the Michigan Division, ${ }^{\prime}$ Medical and Industrial Hygiene Departments, and Health and Environmental Sciences, ${ }^{2}$ Department of Epidemiology, The Dow Chemical Company, Midland, MI 48674, USA

ABSTRACT The prevalence of selected illnesses and symptoms during 1977-85 was compared between 175 employees potentially exposed to the organophosphate insecticide chlorpyrifos and 335 matched controls with no history of exposure to organophosphates. Subjects were subdivided into three exposure intensity groups on the basis of job title and air monitoring data for dose response testing. This classification scheme was shown roughly to correlate with plasma cholinesterase inhibition in the workers. No statistically significant differences in illness or prevalence of symptoms were observed between the exposed and unexposed groups or among the three exposure subgroups. Potentially exposed employees did report symptoms of dizziness and of malaise and fatigue relatively more often than subjects from the comparison group; however, further analyses by exposure level, process area, or time did not support a relation with exposure. No cases of peripheral neuropathy were seen among the exposed workers. Although the sample size was small and the statistical power limited, the cumulative exposures likely to have been experienced by this workforce exceed those to be expected for individuals using the product as recommended. The absence of exposure related adverse effects, including neurological impairment, is reassuring.

Chlorpyrifos (0,0-diethyl-0-(3,5,6-trichloro-2-pyridyl) phosphorothioate) is an organophosphate insecticide shown to have broad activity against several common pests and is widely used in both agricultural and nonagricultural applications. Increasing use of the product has resulted in a corresponding increase in queries about the product's potential to cause human toxicity. The present study was undertaken to determine if employees engaged in the manufacture or formulation of chlorpyrifos experienced more frequent illness during an eight and a half year period than a comparable group of coworkers without a history of exposure to organophosphae.

As with other organophosphate compounds, the principal action of chlorpyrifos is inactivation of acetylcholinesterase through phosphorylation; sufficiently high doses may trigger a cholinergic response. Studies conducted in laboratory animals, however, have shown that plasma cholinesterase is more susceptible to inhibition than erythrocyte cholinesterase and both are depressed by smaller doses of chlorpyrifos than those needed to inhibit brain cholinesterase or produce signs of toxicity. ${ }^{2}$ Studies in human volunteers have shown that chlorpyrifos may

Accepted 15 February 1988 substantially depress plasma cholinesterase with no effect on erythrocyte cholinesterase and without any evidence of a cholinergic response. ${ }^{3}$ Because plasma cholinesterase activity is the most sensitive indicator of exposure to chlorpyrifos, it is often used for medical surveillance of exposed workers.

Chlorpyrifos is considered to have moderate acute toxicity with single dose oral LD50 values in rats ranging from $118-270 \mathrm{mg} / \mathrm{kg}$ for males and 82 $174 \mathrm{mg} / \mathrm{kg}$ for females ${ }^{1}$ and Henck JW, Kociba RJ, mammalian and Environmental Toxicology Laboratory, the Dow Chemical Company unpublished data, 1984). Animal data indicate that it has a moderate potential for absorption through the skin in acutely toxic amounts (Henck JW, Kociba RJ, 1984). Other studies suggest that man may be less likely to absorb acutely toxic amounts than would be predicted from the animal data. ${ }^{3}$ Technical chlorpyrifos has not been shown to be a skin sensitiser in two studies using standard test methods (Henck JW, Lockwood DD, 1978; Carreon RE, Wall JM, 1983; unpublished data); however, some formulations have been shown to be weakly positive.

The subchronic oral toxicity of chlorpyrifos has been evaluated in rats, dogs, and monkeys. Doses in the $0.03-0.15 \mathrm{mg} / \mathrm{kg} /$ day range had no effect on 
plasma or erythrocyte cholinesterase. ${ }^{1}$ Doses above $10 \mathrm{mg} / \mathrm{kg} /$ day are required to produce cholinergic responses. No signs of toxicity other than those associated with cholinesterase depression have been observed in any species.

Human volunteers receiving $0 \cdot 1 \mathrm{mg} / \mathrm{kg} /$ day chlorpyrifos by mouth showed a $66 \%$ reduction in plasma cholinesterase activity after nine days. ${ }^{4}$ No signs or symptoms of toxicity or changes in erythrocyte cholinesterase were observed and plasma cholinesterase concentrations recovered completely within four weeks of exposure. Exposure to $0.03 \mathrm{mg} / \mathrm{kg} /$ day for 21 days resulted in slight, but not statistically significant, depression of plasma cholinesterase; no effect was detected in volunteers receiving $0.014 \mathrm{mg} / \mathrm{kg} /$ day for 28 days.

The low vapour pressure of chlorpyrifos $\left(1.87 \times 10^{-5} \mathrm{~mm} \mathrm{Hg}\right.$ at $\left.25^{\circ} \mathrm{C}\right)$ precludes the generation of acutely toxic vapour concentrations at room temperature. A 13 week nose only vapour inhalation study in rats produced no effect on plasma, erythrocyte, or brain cholinesterase at the highest concentration tested (about $296 \mu \mathrm{g} / \mathrm{m}^{3}$ ) (Corley RA, et al, 1987, unpublished data).

Chlorpyrifos has been evaluated for delayed neurotoxicity in acute and subchronic studies (Rowe LD, et al, 1978; Barna-Lloyd T, et al, 1986; unpublished data). In the acute study doses equal to or twice the LD50 ( 50 or $100 \mathrm{mg} / \mathrm{kg}$, respectively) were administered by mouth to hens and atropine was used to prevent acute lethality. The subchronic study involved daily oral administration of doses of $0,1,5$, or $10 \mathrm{mg} /$ $\mathrm{kg} / \mathrm{day}$ for 13 weeks to hens. No clinical or histopathological evidence for delayed neurotoxicity was observed in either study.

Chlorpyrifos was not carcinogenic in rats fed up to $3.0 \mathrm{mg} / \mathrm{kg} /$ day for two years ${ }^{2}$ and in mice fed up to $1.5 \mathrm{mg} / \mathrm{kg} /$ day for two years (Warner, SD et al, 1980 , unpublished data). Various mutagenicity studies indicate minimal mutagenic potential ${ }^{6-9}$ (and Bruce RJ, Zempel JA, 1986; Gollapudi BB, et al, 1985; Mendrala AL, 1985; unpublished data).

Multigeneration reproduction studies in rats and teratology studies in rats and mice showed no effects on reproductive capacity and produced no increase in fetal malformations ${ }^{10}$ (and Deacon MM, et al, 1980; Thompson DJ, et al, 1971; Dietz FK, et al, 1983; Ouellette JH, et al, 1983; unpublished data).

Studies in animals and man show that chlorpyrifos is rapidly metabolised to 3,5,6-trichloro-2-pyridinol (3,5,6-TCP) which is in turn rapidly eliminated, predominantly in the urine. ${ }^{13}$ Based on urinary excretion of 3,5,6-TCP, less than $3 \%$ of a dermal dose of $5.0 \mathrm{mg} / \mathrm{kg}$ of chlorpyrifos was absorbed by man. ${ }^{3}$ It was concluded that chlorpyrifos and its principal metabolite have a low potential to accumulate in man on repeated exposures.

There have been few observational studies of people exposed to workplace levels of chlorpyrifos. ArP. industrial hygiene and medical surveillance study was: conducted of 25 pest control operators who were? exposed to three organophosphate insecticides? dichlorvos, diazinon, and chlorpyrifos. " Twenty fou hour urines analysed for alkyl phosphates confirmed the presence of metabolites of the three products. Aip monitoring showed mean eight hour exposure levels of $30.95,6.29$, and $7.54 \mu \mathrm{g} / \mathrm{m}^{3}$ of dichlorvos, diazinion $\overrightarrow{0}$ and chlorpyrifos, respectively. The operators were shown to have had a statistically significant inhibition of plasma cholinesterase compared with an age ans sex matched control group. There were no significant differences in the mean erythrocyte cholinesterase values between the groups. Physical examinations showed no apparent toxic effects in the operatof groups.

There have been several unpublished alleged healtb effects associated with the use of chlorpyrifos. Among the most commonly cited are headaches, allergic type reactions (particularly rashes and asthma), and to of lesser extent liver or kidney disease. In general, those effects are not supported by the animal toxicity dati derived under experimental conditions and do not seem plausibly to be related to chlorpyrifos. Neverthe less, the present study was undertaken to determole whether people working with chlorpyrifos may adversely affected.

The Michigan Division of The Dow Chemicab Company, has manufactured chlorpyrifos at itš Midland plant since 1969. Chlorpyrifos has been̊ manufactured in one building, formulated as a liquid: in another, and as a granular material in yet a third. AlB employees assigned to any of those three buildings for? more than one day between 1 January 1977 and 31 Julyọ 1985 were identified from computerised personne $\bar{\sigma}$ records. Job classification titles were provided to industrial hygienists and veteran manufacturing personnel to determine those involving a reasonable potential for exposure to chlorpyrifos. From the 204\% employees originally identified, 175 were determined 3 to have held jobs involving potential exposure ando constituted the study group.

A comparison group was chosen from among othero employees at the plant who had no history of assign ment to those three buildings or of working with organophosphates in a research or manufacturing capacity. These control subjects were individually matched with members from the study group at an approximate ratio of 2:1 on year of birth within five years, year of hire within five years, sex, race, and payc status (hourly or salary). In some instances these criteria had to be relaxed in order to derive at least onematched control for each study subject. None the less, $\frac{T}{-}$ 
Table 1 Distribution of exposed and comparison subjects by matching variables; study of morbidity among employees potentially exposed to chlorpyrifos, 1977-85

\begin{tabular}{|c|c|c|c|c|}
\hline \multirow[b]{2}{*}{ Matching variable } & \multicolumn{2}{|c|}{ Exposed group } & \multicolumn{2}{|c|}{ Comparison group } \\
\hline & $(n=175)$ & $\%$ of Total & $(n=335)$ & $\%$ of Total \\
\hline $\begin{array}{l}\text { Race: } \\
\text { White } \\
\text { Asian } \\
\text { American Indian } \\
\text { Black } \\
\text { Hispanic }\end{array}$ & $\begin{array}{r}154 \\
1 \\
1 \\
14 \\
5\end{array}$ & $\begin{array}{r}88 \cdot 0 \\
0 \cdot 6 \\
0 \cdot 6 \\
8 \cdot 0 \\
2 \cdot 9\end{array}$ & $\begin{array}{r}298 \\
0 \\
1 \\
29 \\
7\end{array}$ & $\begin{array}{c}89 \cdot 0 \\
0 \cdot 3 \\
8 \cdot 7 \\
2 \cdot 1\end{array}$ \\
\hline $\begin{array}{l}\text { Sex: } \\
\text { Men } \\
\text { Women }\end{array}$ & $\begin{array}{r}158 \\
17\end{array}$ & $\begin{array}{r}90 \cdot 3 \\
9 \cdot 7\end{array}$ & $\begin{array}{r}302 \\
33\end{array}$ & $\begin{array}{r}90 \cdot 2 \\
9.9\end{array}$ \\
\hline $\begin{array}{l}\text { Pay status: } \\
\text { Hourly } \\
\text { Non-exempt } \\
\text { Exempt }\end{array}$ & $\begin{array}{r}114 \\
13 \\
48\end{array}$ & $\begin{array}{r}65 \cdot 1 \\
7 \cdot 4 \\
27 \cdot 4\end{array}$ & $\begin{array}{r}219 \\
26 \\
95\end{array}$ & $\begin{array}{r}65 \cdot 4 \\
7.8 \\
26.9\end{array}$ \\
\hline $\begin{array}{l}\text { Difference in birth y } \\
\text { (case-control) }\end{array}$ & & $\begin{array}{l}\text { ean }=-0.12 \\
\text { nge }=-4 \cdot 9 \\
\text { edian }=-0 .\end{array}$ & $\begin{array}{l}2 \text { years; SD } \\
9-7.08 \text { ye } \\
25 \text { years }\end{array}$ & $\begin{array}{l}2 \cdot 87 \text { years } \\
\text { ars }\end{array}$ \\
\hline $\begin{array}{l}\text { Difference in hire ye } \\
\text { (case-control) }\end{array}$ & & $\begin{array}{l}\text { ean }=0.10 \mathrm{y} \\
\text { nge }=-4.9 \\
\text { edian }=0 \text { ye }\end{array}$ & $\begin{array}{l}\text { ears; SD } 2 \cdot 3 \\
6-5 \cdot 24 \text { ye } \\
\text { ars }\end{array}$ & $\begin{array}{l}7 \text { years } \\
\text { ars }\end{array}$ \\
\hline
\end{tabular}

the desired similarity between the two groups was achieved (table 1).

Company medical records of the study, and comparison subjects were abstracted and coded to the International Classification of Diseases, ninth revision, clinical modification (ICD-9-CM) by a nurse (EAM) who is an experienced nosologist. Every effort
Table 2 Distribution of cohort by year of entry into observation and duration of observation; study of morbidity among employees potentially exposed to chlorpyrifos, 1977 85

\begin{tabular}{lccccc}
\hline \multirow{2}{*}{$\begin{array}{l}\text { Year of entry into } \\
\text { observation }\end{array}$} & \multicolumn{6}{c}{ Duration of observation (months) } \\
\cline { 2 - 6 } & $<6$ & $6-18$ & $18-42$ & $>42$ & Total \\
\hline $1977-79$ & 13 & 18 & 12 & 37 & 80 \\
$1980-82$ & 9 & 4 & 24 & 6 & 43 \\
$\geqslant 1983$ & 23 & 18 & 11 & 0 & 52 \\
Total & 45 & 40 & 47 & 43 & 175 \\
\hline
\end{tabular}

was made to keep her "blind" as to the exposure status of each subject. A sample of her work was checked periodically for accuracy and completeness by a physician coinvestigator (FEB). The focus of data abstraction included illnesses and symptoms that affected selected organ systems (gastrointestinal tract and nervous system) of interest, chosen because of known effects of chlorphyrifos in studies of laboratory animals or because of unsubstantiated alleged effects in man.

Any illnesses or symptoms recorded between 1 January 1977 and 31 August 1985 were abstracted. Because chlorpyrifos exerts acute and not delayed effects, only those illnesses and symptoms recorded during the time the subject (or their matched partner) was assigned to a job with potential exposure, or within one month of leaving such a job, were counted in the analysis. Table 2 presents the distribution of

Table 3 Summary of industrial hygiene measurements of chlorpyrifos concentrations by production area; study of morbidity among employees potentially exposed to chlorpyrifos, 1977-85

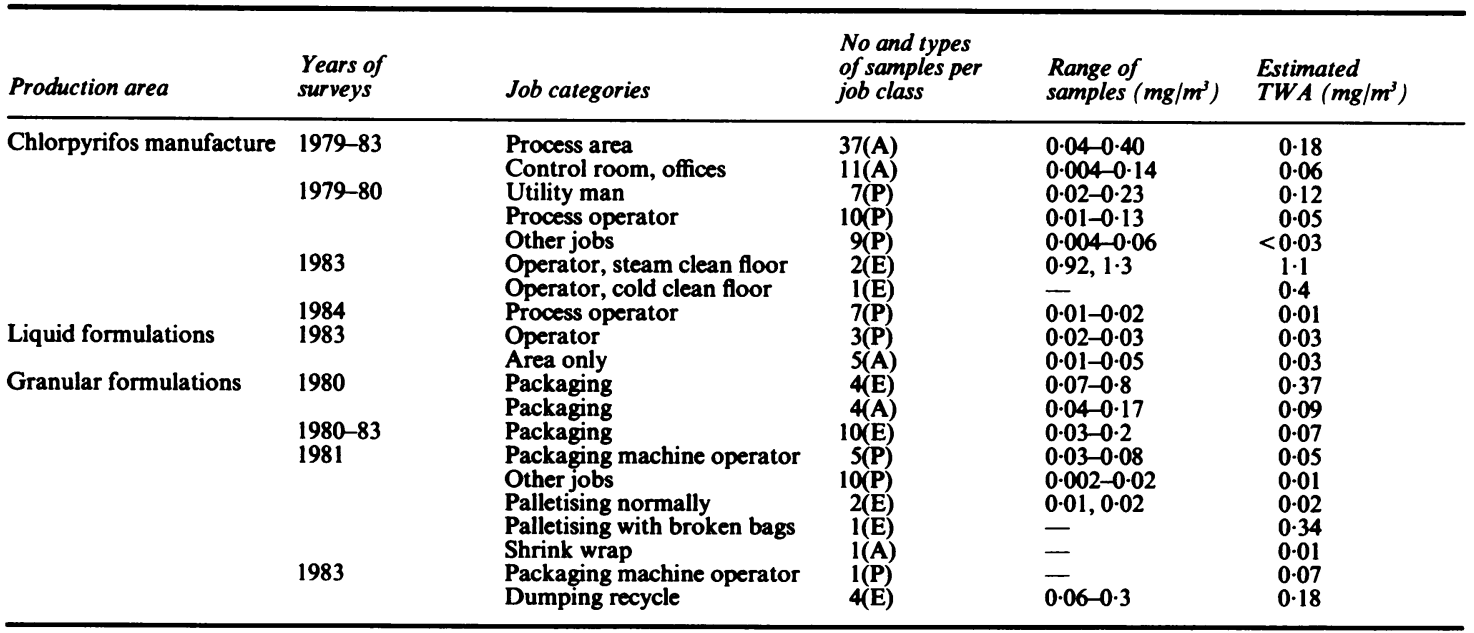

$A=$ Area

$\mathbf{E}=$ Excursion,

$\mathbf{P}=$ Personal sample.

Note: The current American Conference of Governmental Industrial Hygienist's recommended threshold limit value for chlorpyrifos is $\mathbf{0} \cdot \mathbf{2}$ $\mathbf{m g} / \mathbf{m}^{3}$. 
Table 4 Number of prevalent cases and crude risk estimates for selected disease conditions; study of morbidity among employees potentially exposed to chlorpyrifos, 1977-85

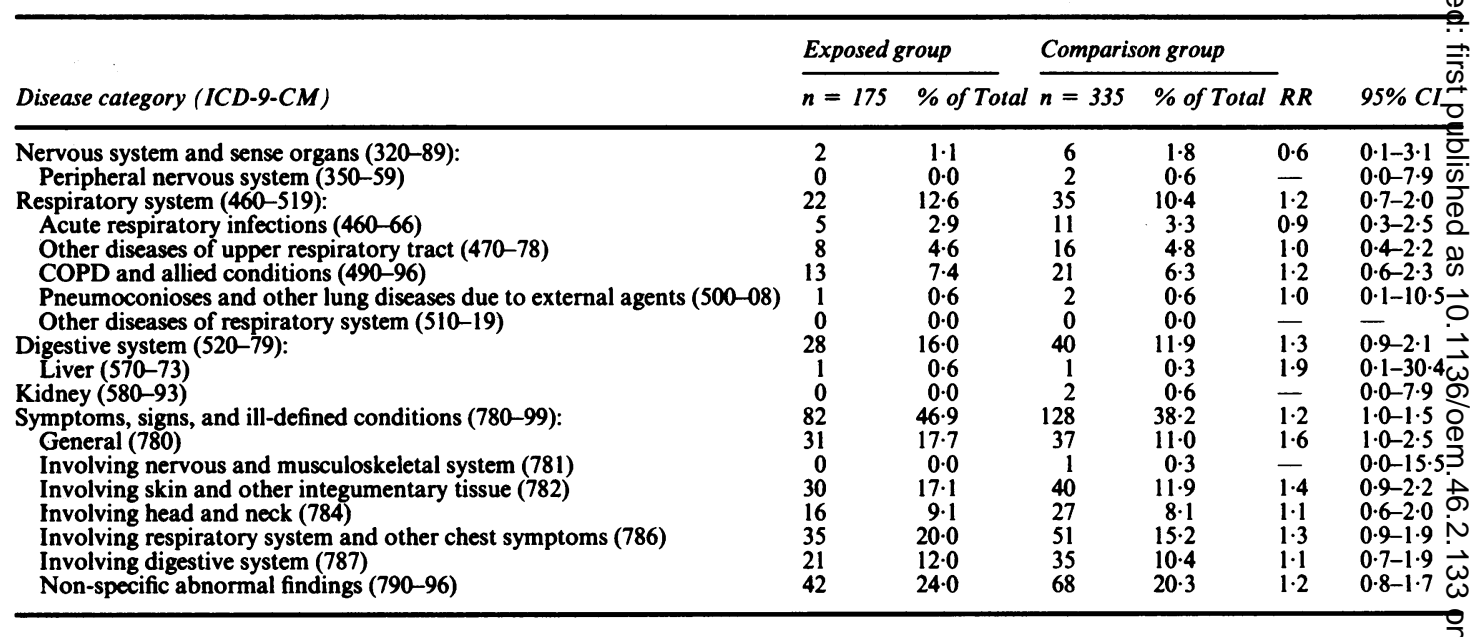

study subjects by year of entry into observation and by the number of years of observation. The median year and age at first observation and months of follow up were $1980,31 \cdot 7$ and $19 \cdot 1$, respectively. Nearly a third of the study group had worked in jobs with potential exposure before the beginning of observation in 1977.

Illnesses and symptoms were grouped into five major and 15 minor categories for analysis. A subject could contribute at most one observation within each category, but possibly several to different categories. It was not always possible to distinguish illness which existed before the follow up period from illness newly occurring during the follow up period. For this reason all diagnostic data were considered to be period prevalence. The relative risk was taken as the measure of association between exposure and disease, and $95 \%$ confidence intervals were computed. A finding was regarded as statistically significant if the $\mathrm{CI}$ excluded the null value of 1.0 . All analyses were performed using software of the Statistical Analysis System. ${ }^{12}$

In addition to recording the diagnoses and their associated dates, the source of the information was also recorded (self report, nurse, company physician, private physician, or laboratory). Histories of using tobacco, alcohol, and cholinergic drugs were abstracted as were the number of periodic voluntary health examinations in which the subject participated. The latter four items were treated as potential confounding variables in a stratified analysis. ${ }^{13}$

In-scope jobs were grouped as high, moderate, or low according to their potential for exposure to chlorpyrifos. This was done based on industrial hygiene surveys (table 3 ) and in consultation with veteran manufacturing personnel. Analyses of illness and symptom prevalence were then done separately within each category to examine for an exposure $\vec{\rho}$ response gradient.

Employees with potential exposure to chlorpyrif had baseline pre-exposure plasma cholinesterase measurements (Micro-Michel method before Octobę: 1983 and Boehringer-Mannheim method thereaffeet and follow up monitoring at roughly monity intervals. This gave us the opportunity to examingothe correlation between a biological index of exposure ang our three categories developed solely from data based on industrial hygiene air monitoring. Cholinesterase inhibition was taken as per cent of change from baseline and linked to exposure categories through th: dates of measurement and job assignment. Meañ inhibition was computed for each subject and weighted mean was calculated for each exposure category. (The ratio of the inverse of the standared error squared to the sum of the inverse of the standarif errors squared was used as the weight.) By this method, the mean cholinesterase inhibition associate with the low exposure category was $19 \cdot 1 \%$ (SD 2.98 with the moderate category $32.1 \%$ (SD 2.8), and wit the high category $32.0 \%$ (SD 5.3). Thus there appeared to be a rough correlation between the classification based on air monitoring data and the degree of plasma cholinesterase inhibition, althoug the latter failed to distinguish between the categories regarded as moderate and high.

\section{Results}

Table 4 presents a summary of illness and symptori prevalence among study and comparison subjects unadjusted for possible confounding factors. Adjuste analyses provided similar results, indicating a lack of 
confounding by use of tobacco, alcohol, or cholinergic medications, or by the number of voluntary periodic medical exams in which a subject participated. There were few differences noted in illness or symptom prevalence and none was statistically significant. Analyses by level of exposure also showed no significant findings.

Among the non-significant differences was the higher recorded prevalence of general symptoms among exposed subjects. This included more frequent reports by the subjects themselves of dizziness; malaise, and fatigue. These reports did not cluster in time, by process area, or estimated degree of exposure.

No cases of peripheral neuropathy were recorded among the study group. The lone case of hepatitis among those potentially exposed was determined to have been viral in origin. One study subject was treated for inhalation of chemical fumes but the offending agent was identified as chlorine. There were no other findings which were regarded as clinically or epidemiologically significant.

\section{Discussion}

An eight and a half year morbidity survey of employees engaged in the manufacture or formulation of chlorpyrifos has not shown them to have experienced significantly more frequent illness or symptoms of illness relative to similar workers with no history of exposure to organophosphates. This is consistent with the predictions from studies in laboratory animals and human volunteers which indicate that adverse clinical effects should not be associated with the levels of exposure experienced by workers in this study. Inhibition of plasma cholinesterase was observed, but without any detectable neuropathology or other illness.

Employees exposed to chlorpyrifos did report symptoms of dizziness and of malaise and fatigue relatively more frequently than did subjects from the comparison group; however, further analyses did not support a relation with exposure.

The present study has several limitations that must be considered. The contingencies of morbidity reporting are varied and complex. Only those patients who perceive themselves to be ill enough to seek medical care and are properly diagnosed actually contribute information.

The sole source of diagnostic information was the employee's medical record, representing a chronological list of visits to the company medical department located on site. Although the department's emphasis has been the diagnosis and treatment of occupational disease, historically the employees more often have sought attention for non-occupational illness and injury. Beginning in the 1960s employees have been offered a periodic examination including: health history, blood chemistries, urine analysis, anth- ropometric measurements, blood pressure, audiometry, visual acuity, pulmonary function and electrocardiogram testing, and chest $x$ ray and haemoccult evaluation. Data from the present study show that $95.4 \%$ of the study group and $91.3 \%$ of the comparison group participated in at least one such examination during the observation period. Hourly employees who are absent from work for more than three days due to illness are required to provide a diagnosis from their private physician, allowing another opportunity to learn of any disease among the workforce.

The sample size $(n=175)$, available for this study, limits the power to detect statistically significant increases in risk of illness in the exposed group. The cumulative exposures likely to have been experienced by this workforce, however, exceed those to be expected for others likely to be in contact with chlorpyrifos when working with the product as recommended. Thus the absence of evidence for adverse effects associated with exposures to chlorpyrifos is reassuring.

We thank Susan B McCollister for her helpful comments on the manuscript.

References

1 World Health Organisation. 1972 evaluation of some pesticide residues in food. Geneva: WHO 1973. (Tech rep series No 525; FAO agricultural studies, No 90 .)

2 McCollister SB, Kociba RJ, Humiston CG, et al. Studies of the acute and long-term oral toxicity of chlorpyrifos (0,0-diethyl-0(3,5,6-trichloro 2-pyridyl) phosphorothioate), Food and Cosmetic Toxicology 1974;12:45-61.

3 Nolan RJ, Rick DL, Freshour NL, Saunders JH. Chlorpyrifos: pharmacokinetics in human volunteers. Toxicol Appl Pharmacol 1984;73:8-15.

4 Coulston F, Golberg L, Griffin T. Safety evaluation of DOWCO 179 in human volunteers. Albany, NY: Institute of Experimental Pathology and Toxicology, Albany Medical College, 1972.

5 Amer SM, Fahmy MA. Cytogenetic effects of pesticides. I. Induction of micronuceli in mouse bone marrow by the insecticide Dursban. Mutat Res 1982;101:247-55.

6 Muscarella DE, Keown JF, Bloom SE. Evaluation of the genotoxic and embryotoxic potential of chlorpyrifos and its metabolites in vivo and in vitro. Environ Mutagen 1984;6:13-23.

7 Poole DC, Simmon VF, Newell GW. In vitro mutagenic activity of fourteen pesticides. Toxicol Appl Pharmacol 1977;41:196.

8 Sobti RC, Krishan A, Pfaffenberger CD. Cytokinetic and cytogenetic effects of some agricultural chemicals on human lymphoid cells in vitro: organophosphates. Mutat Res 1982;102:89-102.

9 Shirasu Y, Moriya M, Kato K, Furuhashi A, Kada T. Mutagenicity screening of pesticides in the microbial system. Mutat Res 1976;40:19-30.

10 Deacon MM, Murray JS, Pilny MK, et al. Embryotoxicity and fetotoxicity of orally administered chlorpyrifos in mice. Toxicol Appl Pharmacol 1980;54:31-40.

11 Hayes AL, Wise RA, Weir FW. Assessment of occupational exposure to organophosphates in pest control operators. American Industrial Hygiene Association Journal 1980;41: 568-75.

12 SAS Institute Inc. SAS user's guide. Basics version, 5th ed. Cary, NC: SAS, 1985:1290.

13 Mantel N, Haenszel W. Statistical aspects of the analysis of data from retrospective studies of disease. JNCI 1959;22:719-48. 